\title{
Common fixed point theorems for non-compatible self-maps in generalized metric spaces
}

\section{Zhongzhi Yang*}

\section{"Correspondence:} zzyang_99@163.com Accounting School, Zhejiang University of Finance and Economics, Hangzhou, 310018, China

\begin{abstract}
By using $R$-weak commutativity of type $\left(A_{g}\right)$ and non-compatible conditions of self-mapping pairs in generalized metric space, without the conditions for the completeness of space and the continuity of mappings, we establish some new common fixed point theorems for two self-mappings. Our results differ from other results already known. An example is provided to support our new result.

MSC: 47H10; 54H25; 54E50

Keywords: generalized metric space; $R$-weakly commuting mappings of type $\left(A_{g}\right)$; non-compatible mapping pairs; common fixed point
\end{abstract}

\section{Introduction and preliminaries}

In 1976, Jungck [1] proved a common fixed point theorem of commuting mappings in a metric space. In 1982, Sessa [2] introduced the concept of weakly commuting mappings, which is a generalization of the concept of commuting mappings, and he has proved some fixed point theorems for weakly commuting mappings. In 1986, Jungck [3] introduced more generalized commuting mappings, called compatible mappings, which are more general than commuting and weakly commuting mappings. These concepts have been useful for obtaining more comprehensive fixed point theorems. In 1992, Dhage [4] introduced the concept of D-metric space. Recently, Mustafa and Sims [5] have shown that most of the results concerning Dhage's $D$-metric spaces are invalid. Therefore, they introduced an improved version of the generalized metric space structure and called it a G-metric space [6].

Based on the notion of generalized metric spaces, Mustafa et al. [7-9], Aydi et al. [10], Aydi [11], Gajié and Stojakovié [12], Zhou and Gu [13] obtained some fixed point results for mappings satisfying different contractive conditions. Shatanawi [14] obtained some fixed point results for $\Phi$-maps in G-metric spaces. Chugh et al. [15] obtained some fixed point results for maps satisfying property $P$ in $G$-metric spaces. In 2010, Manro et al. [16] obtained some fixed point results for expansion mappings in G-metric spaces.

The study of common fixed point problems in G-metric spaces was initiated by Abbas and Rhoades [17]. Subsequently, many authors obtained many common fixed point theorems for the mappings satisfying different contractive conditions; see [18-29] for more details. Recently, some authors have used the (E.A) property in generalized metric space

○2014 Yang; licensee Springer. This is an Open Access article distributed under the terms of the Creative Commons Attribution License (http://creativecommons.org/licenses/by/2.0), which permits unrestricted use, distribution, and reproduction in any medium, provided the original work is properly cited. 
to prove common fixed point results, such as Abbas et al. [30], Mustafa et al. [31], Long et al. [32], Gu and Yin [33], Gu and Shatanawi [34].

Very recently, Jleli and Samet [35] and Samet et al. [36] noticed that some fixed point theorems in the context of a $G$-metric space can be concluded by some existing results in the setting of a (quasi-)metric space. In fact, if the contraction condition of the fixed point theorem on a $G$-metric space can be reduced to two variables instead of three variables, then one can construct an equivalent fixed point theorem in the setting of a usual metric space. More precisely, in $[35,36]$, the authors noticed that $d(x, y)=G(x, y, y)$ forms a quasimetric. Therefore, if one can transform the contraction condition of existence results in a $G$-metric space in such terms, $G(x, y, y)$, then the related fixed point results become the well-known fixed point results in the context of a quasi-metric space.

Now we give basic definitions and some basic results [6], which are helpful for improving our main results.

Definition 1.1 [6] Let $X$ be a nonempty set, and let $G: X \times X \times X \longrightarrow R^{+}$be a function satisfying the following axioms:

(G1) $G(x, y, z)=0$ if $x=y=z$;

(G2) $0<G(x, x, y)$ for all $x, y \in X$ with $x \neq y$;

(G3) $G(x, x, y) \leq G(x, y, z)$ for all $x, y, z \in X$ with $z \neq y$;

(G4) $G(x, y, z)=G(x, z, y)=G(y, z, x)=\cdots$ (symmetry in all three variables); and

(G5) $G(x, y, z) \leq G(x, a, a)+G(a, y, z)$ for all $x, y, z, a \in X$ (rectangle inequality).

Then the function $G$ is called a generalized metric, or more specifically, a $G$-metric on $X$ and the pair $(X, G)$ is called a $G$-metric space.

It is well known that the function $G(x, y, z)$ on the $G$-metric space $X$ is jointly continuous in all three of its variables, and $G(x, y, z)=0$ if and only if $x=y=z$ (see [6]).

Definition 1.2 [6] Let $(X, G)$ be a $G$-metric space, $\left\{x_{n}\right\} \subset X$ be a sequence. Then the sequence $\left\{x_{n}\right\}$ is called:

(i) a $G$-convergent sequence if, for any $\epsilon>0$, there is an $x \in X$ and an $n_{0} \in \mathbb{N}$, such that for all $n, m \geq n_{0}, G\left(x_{n}, x_{m}, x\right)<\epsilon$; i.e. if $\lim _{n, m \rightarrow \infty} G\left(x_{n}, x_{m}, x\right)=0$;

(ii) a G-Cauchy sequence if, for any $\epsilon>0$, there is an $n_{0} \in \mathbb{N}$ (the set of natural numbers) such that for all $n, m, l \geq n_{0}, G\left(x_{n}, x_{m}, x_{l}\right)<\epsilon$; i.e. if $G\left(x_{n}, x_{m}, x_{l}\right) \rightarrow 0$ as $n, m, l \rightarrow \infty$.

A $G$-metric space $(X, G)$ is said to be $G$-complete if every $G$-Cauchy sequence in $(X, G)$ is $G$-convergent in $X$. It is well known that $\left\{x_{n}\right\}$ is $G$-convergent to $x \in X$.

Proposition 1.1 [6] Let $(X, G)$ be a G-metric space, then the following statements are equivalent:

(1) $\left\{x_{n}\right\}$ is G-convergent to $x$;

(2) $G\left(x_{n}, x_{n}, x\right) \rightarrow 0$ as $n \rightarrow \infty$;

(3) $G\left(x_{n}, x, x\right) \rightarrow 0$ as $n \rightarrow \infty$;

(4) $G\left(x_{n}, x_{m}, x\right) \rightarrow 0$ as $n, m \rightarrow \infty$.

Proposition 1.2 [6] Let $(X, G)$ be a G-metric space. Then the function $G(x, y, z)$ is jointly continuous in all of its three variables. 
Definition 1.3 [6] Let $(X, G)$ and $\left(X^{\prime}, G^{\prime}\right)$ be $G$-metric space, and $f:(X, G) \rightarrow\left(X^{\prime}, G^{\prime}\right)$ be a function. Then $f$ is said to be $G$-continuous at a point $a \in X$ if and only if for every $\epsilon>0$, there is $\delta>0$ such that $x, y \in X$ and $G(a, x, y)<\delta$ implies $G^{\prime}(f(a), f(x), f(y))<\epsilon$. A function $f$ is $G$-continuous at $X$ if and only if it is $G$-continuous at all $a \in X$.

Proposition $1.3[6]$ Let $(X, G)$ and $\left(X^{\prime}, G^{\prime}\right)$ be a G-metric space. Then $f: X \rightarrow X^{\prime}$ is $G$ continuous at $x \in X$ if and only if it is $G$-sequentially continuous at $x$, that is, whenever $\left\{x_{n}\right\}$ is G-convergent to $x,\left\{f\left(x_{n}\right)\right\}$ is G-convergent to $f(x)$.

Definition 1.4 [18] The self-mappings $f$ and $g$ of a $G$-metric space $(X, G)$ are said to be compatible if $\lim _{n \rightarrow \infty} G\left(f g x_{n}, g f x_{n}, g f x_{n}\right)=0$ and $\lim _{n \rightarrow \infty} G\left(g f x_{n}, f g x_{n}, f g x_{n}\right)=0$, whenever $\left\{x_{n}\right\}$ is a sequence in $X$ such that $\lim _{n \rightarrow \infty} f x_{n}=\lim _{n \rightarrow \infty} g x_{n}=t$, for some $t \in X$.

In 2010, Manro et al. [16] introduced the concepts of weakly commuting, $R$-weakly commuting mappings, and $R$-weakly commuting mappings of type $(P),\left(A_{f}\right)$, and $\left(A_{g}\right)$ in $G$ metric space as follows.

Definition 1.5 [16] A pair of self-mappings $(f, g)$ of a $G$-metric space are said to be weakly commuting if

$$
G(f g x, g f x, g f x) \leq G(f x, g x, g x), \quad \forall x \in X
$$

Definition 1.6 [16] A pair of self-mappings $(f, g)$ of a $G$-metric space are said to be $R$ weakly commuting if there exists some positive real number $R$ such that

$$
G(f g x, g f x, g f x) \leq R G(f x, g x, g x), \quad \forall x \in X
$$

Remark 1.1 If $R \leq 1$, then $R$-weakly commuting mappings are weakly commuting.

Definition 1.7 [16] A pair of self-mappings $(f, g)$ of a $G$-metric space $(X, G)$ are said to be

(a) $R$-weakly commuting mappings of type $\left(A_{f}\right)$ if there exists some positive real number $R$ such that $G(f g x, g g x, g g x) \leq R G(f x, g x, g x)$, for all $x$ in $X$.

(b) $R$-weakly commuting mappings of type $\left(A_{g}\right)$ if there exists some positive real number $R$ such that $G(g f x, f x x, f x) \leq R G(g x, f x, f x)$, for all $x$ in $X$.

(c) $R$-weakly commuting mappings of type $(P)$ if there exists some positive real number $R$ such that $G(f x, g g x, g g x) \leq R G(f x, g x, g x)$, for all $x$ in $X$.

Proposition 1.4 [6] Every G-metric on $X$ defines a metric $d_{G}$ on $X$ by

$$
d_{G}(x, y)=G(x, y, y)+G(y, x, x), \quad \forall x, y \in X .
$$

For a symmetric G-metric space, one obtains

$$
d_{G}(x, y)=2 G(x, y, y), \quad \forall x, y \in X .
$$

However, if $G$ is not symmetric, then the following inequality holds:

$$
\frac{3}{2} G(x, y, y) \leq d_{G}(x, y) \leq 3 G(x, y, y), \quad \forall x, y \in X .
$$


It is also obvious that

$$
G(x, x, y) \leq 2 G(x, y, y)
$$

\section{Main results}

Theorem 2.1 Let $(X, G)$ be a G-metric space and $(f, g)$ be a pair of non-compatible selfmappings with $\overline{f X} \subset g X$ (here $\overline{f X}$ denotes the closure off $X$ ). Assume the following conditions are satisfied:

$$
\begin{aligned}
& G(f x, f y, f z) \\
& \quad \leq \alpha \max \left\{\begin{array}{c}
G(g x, g y, g z), \frac{G(f x, g x, g x)+G(f y, g y, g y)}{2}, \frac{G(f y, g y, g y)+G(f z, g z, g z)}{2}, \\
\frac{G(f z, g z, g z)+G(f x, g x, g x)}{2}, \frac{G(f x, g y, g z)+G(g x, f y, g z)}{2}, \frac{G(g x, f y, g z)+G(g x, g y, f z)}{2}
\end{array}\right\}
\end{aligned}
$$

for all $x, y, z \in X$. Here $\alpha \in[0,1)$. If $(f, g)$ are a pair of $R$-weakly commuting mappings of type $\left(A_{g}\right)$, then $f$ and $g$ have a unique common fixed point (say $\left.t\right)$ and both $f$ and $g$ are not G-continuous at $t$.

Proof Since $f$ and $g$ are non-compatible mappings, there exists a sequence $\left\{x_{n}\right\} \subset X$, such that

$$
\lim _{n \rightarrow \infty} f x_{n}=\lim _{n \rightarrow \infty} g x_{n}=t, \quad t \in X,
$$

but either $\lim _{n \rightarrow \infty} G\left(f g x_{n}, g f x_{n}, g f x_{n}\right)$ or $\lim _{n \rightarrow \infty} G\left(g f x_{n}, f g x_{n}, f g x_{n}\right)$ does not exist or exists and is different from zero. Since $t \in \overline{f X} \subset g X$, there must exist a $u \in X$ satisfying $t=g u$. We can assert that $f u=g u$. If not, from condition (2.1), we get

$$
\begin{aligned}
& G\left(f u, f x_{n}, f x_{n}\right) \\
& \quad \leq \alpha \max \left\{\begin{array}{c}
G\left(g u, g x_{n}, g x_{n}\right), \frac{G(f u, g u, g u)+G\left(f x_{n}, g x_{n}, g x_{n}\right)}{2}, \frac{G\left(f x_{n}, g x_{n}, g x_{n}\right)+G\left(f x_{n}, g x_{n}, g x_{n}\right)}{2}, \\
\frac{G\left(f x_{n}, g x_{n}, g x_{n}\right)+G(f u, g u, g u)}{2}, \frac{G\left(f u, g x_{n}, g x_{n}\right)+G\left(g u, f x_{n}, g x_{n}\right)}{2}, \frac{G\left(g u, f x_{n}, g x_{n}\right)+G\left(g u, g x_{n}, f x_{n}\right)}{2}
\end{array}\right\} .
\end{aligned}
$$

Letting $n \rightarrow \infty$ at both sides, we obtain

$$
\begin{aligned}
& G(f u, g u, g u) \\
& \quad \leq \alpha \max \left\{\begin{array}{c}
G(g u, g u, g u), \frac{G(f u, g u, g u)+G(g u, g u, g u)}{2}, \frac{G(f u, g u, g u)+G(f u, g u, g u)}{2}, \\
\frac{G(f u, g u, g u)+G(f u, g u, g u)}{2}, \frac{G(f u, g u, g u)+G(g u, f u, g u)}{2}, \frac{G(g u, f u, g u)+G(g u, g u, f u)}{2}
\end{array}\right\} \\
& \quad=\alpha G(f u, g u, g u) .
\end{aligned}
$$

Since $\alpha \in[0,1)$, we get $G(f u, g u, g u)=0$, and so $f u=g u$.

Since $(f, g)$ are a pair of $R$-weakly commuting mappings of type $\left(A_{g}\right)$, we have

$$
G(g f u, f f u, f f u) \leq R G(g u, f u, f u)=0 .
$$

It means $f f u=g f u$. 
Next, we prove $f f u=f u$. In fact, if $f f u \neq f u$, from condition (2.1), $f u=g u$ and $f f u=g f u$, we have

$$
\begin{aligned}
& G(f u, f f u, f f u) \\
& \quad \leq \alpha \max \left\{\begin{array}{c}
G(g u, g f u, g f u), \frac{G(f u, g u, g u)+G(f u, g f u, g f u)}{2}, \frac{G(f u, g f u, g f u)+G(f f u, g f u, g f u)}{2}, \\
\frac{G(f u, g f u, g f u)+G(f u, g u, g u)}{2}, \frac{G(f u, g f u, g f u)+G(g u, f f u, g f u)}{2}, \frac{G(g u, f u, g f u)+G(g u, g f u, f f u)}{2}
\end{array}\right\} \\
& \quad=\alpha G(f u, f f u, f f u) .
\end{aligned}
$$

From $\alpha \in[0,1)$ we have $f u=f f u$, which implies that $f u=f f u=g f u$, and so $t=f u$ is a common fixed point of $f$ and $g$.

Next we prove that the common fixed point $t$ is unique.

Actually, suppose $w$ is also a common fixed point of $f$ and $g$ and $w \neq t$, then using the condition (2.1), we have

$$
G(t, w, w)=G(f t, f w, f w) \leq \alpha G(t, w, w)
$$

which implies that $t=w$, so that uniqueness is proved.

Now, we prove that $f$ and $g$ are not $G$-continuous at $t$. In fact, if $f$ is $G$-continuous at $t$, we consider the sequence $\left\{x_{n}\right\}$; then we have

$$
\lim _{n \rightarrow \infty} f f x_{n}=f t=t, \quad \lim _{n \rightarrow \infty} f g x_{n}=f t=t .
$$

Since $f$ and $g$ are $R$-weakly commuting mappings of type $\left(A_{g}\right)$, we get

$$
G\left(g f x_{n}, f f x_{n}, f f x_{n}\right) \leq R G\left(g x_{n}, f x_{n}, f x_{n}\right),
$$

so that we have

$$
\lim _{n \rightarrow \infty} G\left(g f x_{n}, f f x_{n}, f f x_{n}\right)=0
$$

it follows that

$$
\lim _{n \rightarrow \infty} g f x_{n}=f t
$$

Hence, we can get

$$
\lim _{n \rightarrow \infty} G\left(f g x_{n}, g f x_{n}, g f x_{n}\right)=G(f t, f t, f t)=0
$$

and

$$
\lim _{n \rightarrow \infty} G\left(g f x_{n}, f g x_{n}, f g x_{n}\right)=G(f t, f t, f t)=0 .
$$

This contradicts with $f$ and $g$ being non-compatible, so $f$ is not G-continuous at $t$.

If $g$ is $G$-continuous at $t$, then we have

$$
\lim _{n \rightarrow \infty} g f x_{n}=g t=t, \quad \lim _{n \rightarrow \infty} g g x_{n}=g t=t .
$$


Since $f$ and $g$ are $R$-weakly commuting mappings of type $\left(A_{g}\right)$, we get

$$
G\left(g f x_{n}, f f x_{n}, f f x_{n}\right) \leq R G\left(g x_{n}, f x_{n}, f x_{n}\right),
$$

so that we have

$$
\lim _{n \rightarrow \infty} G\left(g f x_{n}, f f x_{n}, f f x_{n}\right)=0,
$$

and it follows that

$$
\lim _{n \rightarrow \infty} f f x_{n}=g t=f t=t
$$

This contradicts with $f$ being not G-continuous at $t$, which implies that $g$ is not Gcontinuous at $t$. This completes the proof.

Next, we give an example to support Theorem 2.1.

Example 2.1 Let $X=[2,20]$ be a $G$-metric space with

$$
G(x, y, z)=|x-y|+|y-z|+|z-x| .
$$

We define mappings $f$ and $g$ on $X$ by

$$
f x=\left\{\begin{array}{ll}
2, & \text { if } x=2 \text { or } 5<x \leq 20, \\
6, & \text { if } 2<x \leq 5,
\end{array} \quad g x= \begin{cases}2, & \text { if } x=2, \\
18, & \text { if } 2<x \leq 5 \\
\frac{x+1}{3}, & \text { if } 5<x \leq 20\end{cases}\right.
$$

Clearly, from the above functions we know that $\overline{f X} \subset g X$, and the pair $(f, g)$ are noncompatible self-maps. To see that $f$ and $g$ are non-compatible, consider a sequence $\left\{x_{n}\right\}=$ $\left\{5+\frac{1}{n}\right\}$. We have $f x_{n} \rightarrow 2, g x_{n} \rightarrow 2$, $f g x_{n} \rightarrow 6$ and $g f x_{n} \rightarrow 2$. Thus

$$
\lim _{n \rightarrow \infty} G\left(g f x_{n}, f g x_{n}, f g x_{n}\right)=G(2,6,6)=8 \neq 0 .
$$

On the other hand, there exists $R=1$ such that $G(g f x, f x x, f x) \leq R G(g x, f x, f x)$ for all $x$ in $X$, that is, the pair $(f, g)$ are $R$-weakly commuting mappings of type $\left(A_{g}\right)$.

Now we prove that the mappings $f$ and $g$ satisfy the condition (2.1) of Theorem 2.1 with $\alpha=\frac{2}{3}$. For this, let

$$
M(x, y, z)=\max \left\{\begin{array}{c}
G(g x, g y, g z), \frac{G(f x, g x, g x)+G(f y, g y, g y)}{2}, \frac{G(f y, g y, g y)+G(f z, g z, g z)}{2}, \\
\frac{G(f z, g z, g z)+G(f f x, g x, g x)}{2}, \frac{G(f x, g y, g z)+G(g x, f y, g z)}{2}, \frac{G(g x, f y, g z)+G(g x, g y, f z)}{2}
\end{array}\right\} .
$$

We consider the following cases:

Case (1) If $x, y, z \in\{2\} \cup(5,20]$, then we have $G(f x, f y, f z)=G(2,2,2)=0$, and hence (2.1) is obviously satisfied.

Case (2) If $x, y, z \in(2,5]$, then we have $G(f x, f y, f z)=G(6,6,6)=0$, and hence (2.1) is obviously satisfied. 
Case (3) If $x=y=2, z \in(2,5]$, then we have $G(f x, f y, f z)=G(2,2,6)=8$ and $G(g x, g y, g z)=$ $G(2,2,18)=32$. Thus we obtain

$$
G(f x, f y, f z)=8<\frac{2}{3} \cdot 32=\frac{2}{3} G(g x, g y, g z) \leq \frac{2}{3} M(x, y, z) .
$$

Case (4) If $x=z=2, y \in(2,5]$, then we have $G(f x, f y, f z)=G(2,6,2)=8$ and $G(g x, g y, g z)=$ $G(2,18,2)=32$. Thus we obtain

$$
G(f x, f y, f z)=8<\frac{2}{3} \cdot 32=\frac{2}{3} G(g x, g y, g z) \frac{2}{3} \leq M(x, y, z) .
$$

Case (5) If $y=z=2, x \in(2,5]$, then we have $G(f x, f y, f z)=G(6,2,2)=8$ and $G(g x, g y, g z)=$ $G(18,2,2)=32$. Thus we obtain

$$
G(f x, f y, f z)=8<\frac{2}{3} \cdot 32=\frac{2}{3} G(g x, g y, g z) \leq \frac{2}{3} M(x, y, z) .
$$

Case (6) If $x=2, y, z \in(2,5]$, then we have $G(f x, f y, f z)=G(2,6,6)=8$ and $G(g x, g y, g z)=$ $G(2,18,18)=32$. Thus we obtain

$$
G(f x, f y, f z)=8<\frac{2}{3} \cdot 32=\frac{2}{3} G(g x, g y, g z) \leq \frac{2}{3} M(x, y, z) .
$$

Case (7) If $y=2, x, z \in(2,5]$, then we have $G(f x, f y, f z)=G(6,2,6)=8$ and $G(g x, g y, g z)=$ $G(18,2,18)=32$. Thus we obtain

$$
G(f x, f y, f z)=8<\frac{2}{3} \cdot 32=\frac{2}{3} G(g x, g y, g z) \leq \frac{2}{3} M(x, y, z)
$$

Case (8) If $z=2, x, y \in(2,5]$, then we have $G(f x, f y, f z)=G(6,6,2)=8$ and $G(g x, g y, g z)=$ $G(18,18,2)=32$. Thus we obtain

$$
G(f x, f y, f z)=8<\frac{2}{3} \cdot 32=\frac{2}{3} G(g x, g y, g z) \leq \frac{2}{3} M(x, y, z) .
$$

Case (9) If $x, y \in(2,5], z \in(5,20]$, then we have $G(f x, f y, f z)=G(6,6,2)=8$ and

$$
\frac{G(f x, g x, g x)+G(f y, g y, g y)}{2}=\frac{G(6,18,18)+G(6,18,18)}{2}=24 .
$$

Thus we obtain

$$
G(f x, f y, f z)=8<\frac{2}{3} \cdot 24=\frac{2}{3} \cdot \frac{G(f x, g x, g x)+G(f y, g y, g y)}{2} \leq \frac{2}{3} M(x, y, z) .
$$

Case (10) If $x, z \in(2,5], y \in(5,20]$, then we have $G(f x, f y, f z)=G(6,2,6)=8$ and

$$
\frac{G(f z, g z, g z)+G(f x, g x, g x)}{2}=\frac{G(6,18,18)+G(6,18,18)}{2}=24 \text {. }
$$

Thus we obtain

$$
G(f x, f y, f z)=8<\frac{2}{3} \cdot 24=\frac{2}{3} \cdot \frac{G(f z, g z, g z)+G(f x, g x, g x)}{2} \leq \frac{2}{3} M(x, y, z) .
$$


Case (11) If $y, z \in(2,5], x \in(5,20]$, then we have $G(f x, f y, f z)=G(2,6,6)=8$ and

$$
\frac{G(f y, g y, g y)+G(f z, g z, g z)}{2}=\frac{G(6,18,18)+G(6,18,18)}{2}=24 .
$$

Thus we obtain

$$
G(f x, f y, f z)=8<\frac{2}{3} \cdot 32=\frac{2}{3} \cdot \frac{G(f y, g y, g y)+G(f z, g z, g z)}{2} \leq \frac{2}{3} M(x, y, z) .
$$

Case (12) If $x, y \in(5,20], z \in(2,5]$, then we have $G(f x, f y, f z)=G(2,2,6)=8$ and

$$
\frac{G(f x, g y, g z)+G(g x, f y, g z)}{2}=\frac{G\left(2, \frac{y+1}{3}, 18\right)+G\left(\frac{x+1}{3}, 2,18\right)}{2}=32 .
$$

Thus we obtain

$$
G(f x, f y, f z)=8<\frac{2}{3} \cdot 32=\frac{2}{3} \cdot \frac{G(f x, g y, g z)+G(g x, f y, g z)}{2} \leq \frac{2}{3} M(x, y, z) .
$$

Case (13) If $x, z \in(5,20], y \in(2,5]$, then we have $G(f x, f y, f z)=G(2,6,2)=8$ and

$$
\frac{G(f x, g x, g x)+G(f y, g y, g y)}{2}=\frac{G\left(2, \frac{x+1}{3}, \frac{x+1}{3}\right)+G(6,18,18)}{2}=10+\frac{x+1}{3} \in(12,17] .
$$

Thus we obtain

$$
G(f x, f y, f z)=8=\frac{2}{3} \cdot 12<\frac{2}{3} \cdot \frac{G(f x, g x, g x)+G(f y, g y, g y)}{2} \leq \frac{2}{3} M(x, y, z) .
$$

Case (14) If $y, z \in(5,20], x \in(2,5]$, then we have $G(f x, f y, f z)=G(6,2,2)=8$ and

$$
\frac{G(f x, g x, g x)+G(f y, g y, g y)}{2}=\frac{G(6,18,18)+G\left(2, \frac{y+1}{3}, \frac{y+1}{3}\right)}{2}=10+\frac{y+1}{3} \in(12,17] .
$$

Thus we obtain

$$
G(f x, f y, f z)=8=\frac{2}{3} \cdot 12<\frac{G(f x, g x, g x)+G(f y, g y, g y)}{2} \leq \frac{2}{3} M(x, y, z) .
$$

Case (15) If $x=2, y \in(2,5], z \in(5,20]$, then we have $G(f x, f y, f z)=G(2,6,2)=8$ and

$$
\frac{G(f x, g x, g x)+G(f y, g y, g y)}{2}=\frac{G(2,2,2)+G(6,18,18)}{2}=12 .
$$

Thus we obtain

$$
G(f x, f y, f z)=8=\frac{2}{3} \cdot \frac{G(f x, g x, g x)+G(f y, g y, g y)}{2} \leq \frac{2}{3} M(x, y, z) .
$$

Case (16) If $x=2, y \in(5,20], z \in(2,5]$, then we have $G(f x, f y, f z)=G(2,2,6)=8$ and

$$
\frac{G(f z, g z, g z)+G(f x, g x, g x)}{2}=\frac{G(6,18,18)+G(2,2,2)}{2}=12 .
$$


Thus we obtain

$$
G(f x, f y, f z)=8=\frac{2}{3} \cdot \frac{G(f z, g z, g z)+G(f x, g x, g x)}{2} \leq \frac{2}{3} M(x, y, z) .
$$

Case (17) If $x \in(2,5], y=2, z \in(5,20]$, then we have $G(f x, f y, f z)=G(6,2,2)=8$ and

$$
\frac{G(f x, g x, g x)+G(f y, g y, g y)}{2}=\frac{G(6,18,18)+G(2,2,2)}{2}=12 \text {. }
$$

Thus we obtain

$$
G(f x, f y, f z)=8=\frac{2}{3} \cdot \frac{G(f x, g x, g x)+G(f y, g y, g y)}{2} \leq \frac{2}{3} M(x, y, z) .
$$

Case (18) If $x \in(5,20], y=2, z \in(2,5]$, then we have $G(f x, f y, f z)=G(2,2,6)=8$ and

$$
\frac{G(f y, g y, g y)+G(f z, g z, g z)}{2}=\frac{G(2,2,2)+G(6,18,18)}{2}=12 \text {. }
$$

Thus we obtain

$$
G(f x, f y, f z)=8=\frac{2}{3} \cdot \frac{G(f y, g y, g y)+G(f z, g z, g z)}{2} \leq \frac{2}{3} M(x, y, z) .
$$

Case (19) If $x \in(2,5], y \in(5,20], z=2$, then we have $G(f x, f y, f z)=G(6,2,2)=8$ and

$$
\frac{G(f z, g z, g z)+G(f x, g x, g x)}{2}=\frac{G(2,2,2)+G(6,18,18)}{2}=12 .
$$

Thus we obtain

$$
G(f x, f y, f z)=8=\frac{2}{3} \cdot \frac{G(f z, g z, g z)+G(f x, g x, g x)}{2} \leq \frac{2}{3} M(x, y, z) .
$$

Case (20) If $x \in(5,20], y \in(2,5], z=2$, then we have $G(f x, f y, f z)=G(2,6,2)=8$ and

$$
\frac{G(f y, g y, g y)+G(f z, g z, g z)}{2}=\frac{G(6,18,18)+G(2,2,2)}{2}=12 .
$$

Thus we obtain

$$
G(f x, f y, f z)=8=\frac{2}{3} \cdot \frac{G(f y, g y, g y)+G(f z, g z, g z)}{2} \leq \frac{2}{3} M(x, y, z) .
$$

Then in all the above cases, the mappings $f$ and $g$ satisfy the condition (2.1) of Theorem 2.1 with $\alpha=\frac{2}{3}$, so that all the conditions of Theorem 2.1 are satisfied. Moreover, 2 is the unique common fixed point of $f$ and $g$.

Theorem 2.2 Let $(X, G)$ be a $G$-metric space and let $(f, g)$ be a pair of non-compatible self-mappings such that

$$
\begin{aligned}
& G(f x, f y, f z) \\
& \quad \leq \alpha \max \left\{G(g x, g y, g z), G(f x, g y, g z), G(f y, g y, g z), \frac{G(f z, g x, g y)+G(f y, g x, g z)}{2}\right\}
\end{aligned}
$$

for any $x, y, z \in X$. Here $\alpha \in[0,1)$. Assume the following conditions hold: 
(i) for any sequence $\left\{x_{n}\right\}$ that satisfies the condition $\lim _{n \rightarrow \infty} f x_{n}=\lim _{n \rightarrow \infty} g x_{n}=t \in X$, we have $\lim _{n \rightarrow \infty} f f x_{n}=f t$ and $\lim _{n \rightarrow \infty} g f x_{n}=g t$;

(ii) $(f, g)$ are a pair of $R$-weakly commuting mappings of type $\left(A_{g}\right)$.

Then $f$ and $g$ have a unique common fixed point in $X$.

Proof Since $f$ and $g$ are non-compatible mappings, there exists a sequence $\left\{x_{n}\right\} \subset X$, such that

$$
\lim _{n \rightarrow \infty} f x_{n}=\lim _{n \rightarrow \infty} g x_{n}=t, \quad t \in X,
$$

but, either $\lim _{n \rightarrow \infty} G\left(f g x_{n}, g f x_{n}, g f x_{n}\right)$ or $\lim _{n \rightarrow \infty} G\left(g f x_{n}, f g x_{n}, f g x_{n}\right)$ does not exist or exists and is different from zero.

From condition (i), we have

$$
\lim _{n \rightarrow \infty} f f x_{n}=f t, \quad \lim _{n \rightarrow \infty} g f x_{n}=g t .
$$

Since $(f, g)$ are a pair of $R$-weakly commuting mappings of type $\left(A_{g}\right)$, we can get

$$
G\left(g f x_{n}, f f x_{n}, f f x_{n}\right) \leq R G\left(g x_{n}, f x_{n}, f x_{n}\right) .
$$

Letting $n \rightarrow \infty$, we have $G(g t, f t, f t) \leq R G(t, t, t)=0$. Thus we know $f t=g t$.

From the condition (2.2), we have

$$
\begin{aligned}
G\left(f t, f x_{n}, f x_{n}\right) & \\
\leq & \alpha \max \left\{G\left(g t, g x_{n}, g x_{n}\right), G\left(f t, g x_{n}, g x_{n}\right), G\left(f x_{n}, g x_{n}, g x_{n}\right),\right. \\
& \left.\frac{G\left(f x_{n}, g t, g x_{n}\right)+G\left(f x_{n}, g t, g x_{n}\right)}{2}\right\} .
\end{aligned}
$$

Letting $n \rightarrow \infty$, we get

$$
\begin{aligned}
G(f t, t, t) & \leq \alpha \max \left\{G(g t, t, t), G(f t, t, t), G(t, t, t), \frac{G(t, g t, t)+G(t, g t, t)}{2}\right\} \\
& =\alpha G(f t, t, t) .
\end{aligned}
$$

Since $\alpha \in[0,1)$, therefore, $G(f t, t, t)=0$. Thus, we get $t=f t=g t$.

Suppose $w$ is another fixed point of $f$ and $g$ and $w \neq t$. Letting $x=t, y=w, z=w$ under the condition (2.2), we obtain

$$
\begin{aligned}
& G(f t, f w, f w) \\
& \quad \leq \alpha \max \left\{G(g t, g w, g w), G(f t, g w, g w), G(f w, g w, g w), \frac{G(f w, g t, g w)+G(f w, g t, g w)}{2}\right\} \\
& \quad=\alpha \max \left\{G(t, w, w), G(t, w, w), G(w, w, w), \frac{G(w, t, w)+G(w, t, w)}{2}\right\} \\
& \quad=\alpha G(t, w, w) .
\end{aligned}
$$


Since $\alpha \in[0,1)$, we find that $G(t, w, w)=0$. Therefore, we have $t=w$. So, the common fixed point of $f$ and $g$ is unique. Thus, we complete the proof.

\section{Competing interests}

The author declares that they have no competing interests.

\section{Acknowledgements}

The author is grateful to the editor and the reviewer for suggestions, which improved the contents of the article.

Received: 21 February 2014 Accepted: 17 June 2014 Published: 23 Jul 2014

\section{References}

1. Jungck, G: Commuting mappings and fixed point. Am. Math. Mon. 83, 261-263 (1976)

2. Sessa, S: On a weak commutativity conditions of mappings in fixed point considerations. Publ. Inst. Math. (Belgr.) 32(46), 146-153 (1982)

3. Jungck, G: Compatible mappings and common fixed points. Int. J. Math. Sci. 9(4), 771-779 (1986)

4. Dhage, BC: Generalized metric spaces and mappings with fixed point. Bull. Calcutta Math. Soc. 84, 329-336 (1992)

5. Mustafa, Z, Sims, B: Some remarks concerning D-metric spaces. In: Proceedings of International Conference on Fixed Point Theory and Applications, Valencia, Spain, July 13-19, pp. 189-198. Yokohama Publishers, Yokohama (2004)

6. Mustafa, Z, Sims, B: A new approach to a generalized metric space. J. Nonlinear Convex Anal. 7(2), $289-297$ (2006)

7. Mustafa, Z, Obiedat, H, Awawdeh, F: Some fixed point theorems for mappings on complete G-metric space. Fixed Point Theory Appl. 2008, Article ID 189870 (2008)

8. Mustafa, Z, Sims, B: Fixed point theorems for contractive mappings in complete G-metric spaces. Fixed Point Theory Appl. 2009, Article ID 917175 (2009)

9. Mustafa, Z, Khandagji, M, Shatanawi, W: Fixed point results on complete G-metric spaces. Studia Sci. Math. Hung. 48(3), 304-319 (2011)

10. Aydi, H, Shatanawi, W, Vetro, C: On generalized weakly G-contraction mapping in G-metric spaces. Comput. Math. Appl. 62(11), 4222-4229 (2011)

11. Aydi, H: A fixed point result involving a generalized weakly contractive condition in G-metric spaces. Bull. Math. Anal. Appl. 3(4), 180-188 (2011)

12. Gajié, L, Stojakovié, M: On Ćirié generalization of mappings with a contractive iterate at a point in G-metric spaces. Appl. Math. Comput. 219(1), 435-441 (2012)

13. Zhou, S, Gu, F: Some new fixed points in G-metric spaces. J. Hangzhou Norm. Univ., Nat. Sci. Ed. 11(1), 47-50 (2012)

14. Shatanawi, W: Fixed point theory for contractive mappings satisfying $\Phi$-maps in $G$-metric spaces. Fixed Point Theory Appl. 2010, Article ID 181650 (2010)

15. Chugh, R, Kadian, T, Rani, A, Rhoades, BE: Property P in G-metric spaces. Fixed Point Theory Appl. 2010, Article ID $401684(2010)$

16. Manro, S, Bhatia, SS, Kumar, S: Expansion mapping theorems in G-metric spaces. Int. J. Contemp. Math. Sci. 5(51), 2529-2535 (2010)

17. Abbas, M, Rhoades, BE: Common fixed point results for noncommuting mappings without continuity in generalized metric spaces. Appl. Math. Comput. 215(1), 262-269 (2009)

18. Vats, RK, Kumar, S, Sihag, V: Some common fixed point theorem for compatible mappings of type $(A)$ in complete G-metric space. Adv. Fuzzy Math. 6(1), 27-38 (2011)

19. Abbas, M, Nazir, T, Radenović, S: Some periodic point results in generalized metric spaces. Appl. Math. Comput. 217(8), 4094-4099 (2010)

20. Abbas, M, Khan, SH, Nazir, T: Common fixed points of $R$-weakly commuting maps in generalized metric spaces. Fixed Point Theory Appl. 2011, Article ID 784595 (2011)

21. Gu, F: Common fixed point theorems for six mappings in generalized metric spaces. Abstr. Appl. Anal. 2012, Article ID $379212(2012)$

22. Gu, F: Some new common coupled fixed point results in two generalized metric spaces. Fixed Point Theory Appl. 2013, Article ID 181 (2013)

23. Gu, F, Yang, Z: Some new common fixed point results for three pairs of mappings in generalized metric spaces. Fixed Point Theory Appl. 2013, Article ID 174 (2013)

24. Gu, F, Ye, H: Common fixed point theorems of Altman integral type mappings in G-metric spaces. Abstr. Appl. Anal. 2012, Article ID 630457 (2012)

25. Ye, H, Gu, F: Common fixed point theorems for a class of twice power type contraction maps in G-metric spaces. Abstr. Appl. Anal. 2012, Article ID 736214 (2012)

26. Kaewcharoen, A: Some common fixed point theorems for contractive mappings satisfying $\Phi$-maps in G-metric spaces. Banach J. Math. Anal. 6(1), 101-111 (2012)

27. Tahat, N, Aydi, H, Karapınar, E, Shatanawi, W: Common fixed points for single-valued and multi-valued maps satisfying a generalized contraction in G-metric spaces. Fixed Point Theory Appl. 2012, Article ID 48 (2012)

28. Popa, V, Patriciu, AM: A general fixed point theorem for pairs of weakly compatible mappings in G-metric spaces. J. Nonlinear Sci. Appl. 5, 151-160 (2012)

29. Gugnani, M, Aggarwal, M, Chugh, R: Common fixed point results in G-metric spaces and applications. Int. J. Comput. Appl. 43(11), 38-42 (2012)

30. Abbas, M, Nazir, T, Dorić, D: Common fixed point of mappings satisfying (E.A) property in generalized metric spaces Appl. Math. Comput. 218(14), 7665-7670 (2012)

31. Mustafa, Z, Aydi, H, Karapınar, E: On common fixed points in G-metric spaces using (E.A) property. Comput. Math. Appl. 64(6), 1944-1956 (2012) 
32. Long, W, Abbas, M, Nazir, T, Radenović, S: Common fixed point for two pairs of mappings satisfying (E.A) property in generalized metric spaces. Abstr. Appl. Anal. 2012, Article ID 394830 (2012)

33. Gu, F, Yin, Y: Common fixed point for three pairs of self-maps satisfying common (E.A) property in generalized metric spaces. Abstr. Appl. Anal. 2013, Article ID 808092 (2013)

34. Gu, F, Shatanawi, W: Common fixed point for generalized weakly G-contraction mappings satisfying common (E.A) property in G-metric spaces. Fixed Point Theory Appl. 2013, Article ID 48 (2013)

35. Jleli, M, Samet, B: Remarks on G-metric spaces and fixed point theorems. Fixed Point Theory Appl. 2012, Article ID 210 (2012)

36. Samet, B, Vetro, C, Vetro, F: Remarks on G-metric spaces. Int. J. Anal. 2013, Article ID 917158 (2013)

10.1186/1029-242X-2014-275

Cite this article as: Yang: Common fixed point theorems for non-compatible self-maps in generalized metric spaces. Journal of Inequalities and Applications 2014, 2014:275

\section{Submit your manuscript to a SpringerOpen ${ }^{\circ}$ journal and benefit from:}

- Convenient online submission

- Rigorous peer review

- Immediate publication on acceptance

- Open access: articles freely available online

- High visibility within the field

- Retaining the copyright to your article 